\title{
Illeïtat, turisme i urbanització a les Illes Balears
}

\author{
Antoni Pons Esteva \\ Universitat de les Illes Balears. Departament de Geografia \\ tpons@gaat.es
}

Rebut: abril de 2017

Acceptat: gener de 2018

Publicat: març de 2019

\section{Resum}

Dos factors clau han condicionat l'artificialització del sòl a les Illes Balears: la illeïtat, funció lligada al fet insular, i el turisme. La illeïtat, entesa en termes de desconnexió respecte al continent i de mida reduïda a les illes, ha condicionat un grau més baix d'urbanització de la costa balear respecte a la de les regions continentals de l'àrea mediterrània. A part d'això, les illes més grans, com ara Mallorca, i les més ben comunicades amb l'exterior, com ara Mallorca o Eivissa, han assolit uns graus més elevats d'urbanització que aquelles més petites, com ara Formentera, o més mal comunicades, com ara Menorca o Formentera. La condició insular, en canvi, ha estat un factor d'atracció de visitants. Les illes són importants destinacions turístiques i en aquest sentit les Balears constitueixen un dels principals centres d'interès de la Mediterrània. El turisme requereix espais de producció, en conseqüència, l'artificialització del litoral esdevé una mesura que en reflecteix el grau de pressió que pateix.

Paraules clau: urbanització; turisme; illeïtat; Illes Balears; tècniques d'anàlisi espacial

\section{Resumen. Isleidad, turismo y urbanización en las Islas Baleares}

Dos factores clave han condicionado la artificialización del suelo en las Islas Baleares: la isleidad, función ligada al hecho insular, y el turismo. La isleidad, entendida en términos de desconexión respecto del continente y de tamaño reducido de las islas, ha condicionado el menor grado de urbanización de la costa de Baleares respecto de la de las regiones continentales del área mediterránea. Además, las islas más grandes, como Mallorca, y las mejor comunicadas con el exterior, como Mallorca o Ibiza, han alcanzado también mayores grados de urbanización que aquellas más pequeñas, como Formentera, o peor comunicadas, como Menorca o Formentera. La condición insular, en cambio, ha constituido un factor de atracción de visitantes. Las islas son importantes destinos turísticos y las Baleares representan uno de los principales del Mediterráneo. El turismo requiere de espacios de producción y, como consecuencia, la artificialización del litoral es una medida que refleja su grado de presión.

Palabras clave: urbanización; turismo; isleidad; Islas Baleares; técnicas de análisis espacial 


\section{Résumé. Illéité, tourisme et urbanisation dans les Iles Baléares}

Deux facteurs clés ont conditionné l'artificialité du sol dans les îles Baléares : la fonction l'îléité, fonction liée au fait insulaire, et le tourisme. D'une part, l'îléité, comprise en termes de déconnexion de la partie continentale et de taille réduite des îles, a conditionné le plus faible degré d'urbanisation de la côte des îles Baléares par rapport aux régions continentales de la zone méditerranéenne à proximité. En outre, les îles plus grande, telle que Majorque, ou mieux connectées avec l'extérieur, comme Majorque ou Ibiza, ont également atteint des niveaux plus élevés de développement que les îles plus petites, telles que Formentera, ou moins bien connectées, comme Minorque ou Formentera. D'autre part, la condition insulaire a été un facteur d'attraction touristique, les îles sont généralement d'importantes destinations touristiques et les îles Baléares représente l'une des principales destinations de la Méditerranée. Le tourisme requiert des espaces de production et par conséquent, l'artificialité du littoral constitue une mesure qui reflète son degré de pression.

Mots-clés: urbanisation; tourisme; Îléité; Baléares; techniques d'analyse spatiale

\section{Abstract. Islandness, tourism and urbanization in the Balearic Islands}

Islandness, a function linked to the insular experience, and tourism are two key factors that have conditioned the urbanization process in the Balearic Islands. Islandness, understood as a disconnection from the mainland and in terms of the small size of the islands, has conditioned the lower degree of urbanization of the Balearic coast in comparison to the nearby continental Mediterranean regions. Furthermore, larger islands, such as Mallorca, and those that are better communicated with the exterior, such as Mallorca or Ibiza, have also experienced higher degrees of urbanization than smaller ones, like Formentera, or worse connected ones, like Menorca or Formentera. On the other hand, the island condition has been an attraction factor for the tourism industry. Generally, islands are important tourist destinations and the Balearic Islands are one of the main tourist spots of the Mediterranean. Tourism requires spaces of production and the urbanization of the coastline reflects the degree of tourism pressure.

Keywords: urbanization; tourism; islandness; Balearic Islands; spatial analysis techniques

\section{Sumari}

\section{Introducció $\quad 5$. Mètode}

2. Artificialització del sòl. La urbanització de les Illes Balears

3. Les illes en la literatura geogràfica

4. Hipòtesis i objectius
6. Resultats

7. Discussió i explicació dels resultats

8. Conclusions

Referències bibliogràfiques 


\section{Introducció}

Des de mitjan segle XX moltes economies insulars periferiques o semiperiferiques s'han especialitzat en el turisme, el fenomen que ha esdevingut la força impulsora principal de la urbanització en aquelles zones (Judd i Fanstein, 1999; Judd, 2003). Les Illes Balears són un clar exemple d'aquest fenomen, atès que constitueixen la destinació turística insular principal de la Mediterrània en termes de nombre de visitants (Ruggieri, 2011).

Inicialment, l'article fa una síntesi de l'estat de la qüestió dels temes clau tractats: illeïtat, turisme i artificialització del sòl. Posteriorment, s'hi defineixen els objectius del treball, que se centren en la manera com la illeïtat i el turisme han condicionat el grau d'artificialització del sòl a les Illes Balears. Amb la finalitat d'assolir aquests objectius, s'ha dissenyant i s'ha implementat un model de regressió per a les Illes Balears i les Canàries, els resultats del qual ajuden a interpretar i a explicar com la situació insular i l'activitat turística han condicionat l'artificialització litoral de les illes.

\section{Artificialització del sòl. La urbanització de les Illes Balears}

El treball centra la seva anàlisi en les transformacions relacionades amb el procés d'urbanització entesa, observada i analitzada des d'una perspectiva física i morfològica. És a dir, allò que s'ha definit com a urbs, complementari a les anàlisis de la civitas i de la polis (Capel, 2003: 10). Aquí utilitzarem, per tant, la urbanització com a sinònim d'artificialització, en línia amb la definició de superficie artificial que s'utilitza a la nomenclatura del CORINE Land Cover (CLC) i que es refereix al teixit urbà, continu i discontinu d'àrees residencials, industrials, comercials, de transports, de carreteres, de xarxes de ferrocarril, d'abocadors, de llocs d'extracció i, també, d'àrees verdes urbanes.

A les illes, aquestes superfícies artificials estan condicionades per la pròpia condició insular, que, en el nostre cas, esdevé un factor clau que cal considerar a l'hora d'estudiar i d'interpretar el procés d'expansió de la urbanització.

El present treball s'emmarca en la línia d'altres estudis sobre l'artificialització del sòl realitzats durant les darreres dècades, especialment en altres regions del sud d'Europa i al litoral mediterrani. Molts d'autors han posat èmfasi en els efectes d'una nova morfologia urbana sorgida a la segona meitat de segle XX i caracteritzada per la ciutat difusa (Indovina, 1998; Nello, 1998), la suburbanització i la periurbanització (Dematteis, 1998), la ciutat dispersa (Monclús, 1998), la postmetròpolis (Soja, 2008), etc. La urbanització difusa es defineix de maneres diferents, a vegades en sentit funcional — aquella que és el resultat de les noves pautes de mobilitat fruit de l'expansió en l'ús del cotxe i la millora de les comunicacions-, a vegades en sentit morfològic, dominant els processos d'expansió centrífuga de la urbanització o la dispersió dels teixits urbans sobre el territori, en lloc de concentració. Algunes característiques morfològiques d'aquests processos serien les següents: intensitats inferiors dels fenòmens urbans amb patrons més extensius, territori puntejat per centres urbans 
de mitjanes i petites dimensions al llarg d'una densa xarxa viària, matriu rural que roman cada vegada més diluïda per la dinàmica de la urbanització, etc.

D'altra banda, existeixen nombrosos estudis sobre l'ocupació del territori i sobre els efectes provocats per la urbanització turística en zones litorals. Algunes vegades la investigació se centra en els impactes, ja sigui en forma de pèrdua d'espais naturals o rurals, els que tenen lloc en el paisatge o els que deriven de la sobreexplotació de recursos naturals (Burak et al., 2004; Carrascal i Pérez Villegas, 1998; Sabaté, 2015). Altres vegades el focus se situa en la caracterització dels processos d'expansió de la urbanització i la transformació dels models d'assentaments litorals (Cuadrado et al., 2006).

La urbanització turística litoral és un fet estès a bona part de la Mediterrània europea (Lentidou i Tourkomenis, 2009), on les àrees costaneres han esdevingut en molts indrets un continu de superfícies artificials. L'increment d'espais urbanitzats de baixa densitat a la costa mediterrània és una de les característiques principals del procés d'artificialització del sòl a l'Estat espanyol (OSE, 2007), que coincideixen amb bona mesura amb les regions on va tenir més importància la bombolla immobiliària abans de la crisi financera (Burriel, 2016). S’ha passat d'un sistema nodal de ciutats portuàries i petits assentaments a un model de xarxa densa articulat a la vora de la mar. Existeixen estudis precursors sobre aquesta temàtica: a la costa mediterrània catalana, concretament a la Costa Brava (Emmi i Santigosa, 1989), o uns altres de més recents a l'àmbit de la costa valenciana (Ezquerra et al., 1999; Martí i Nolasco, 2011; Rico et al., 2014; Zornoza, 2013) o andalusa (Villar, 2011; Almeida i Cortés, 2011), a la Manga de la Regió de Múrcia (García-Ayllón, 2015), al Llenguadoc-Rosselló (Marez, 2012), a Canàries (González i Sobral, 2011; Simancas et al., 2011), etc.

A l'arxipèlag balear, en poc més de mig segle s'ha produït una ràpida transformació econòmica que ha cristal.litzat, entre altres aspectes, en la construcció de centres turístics costaners i, en general, en la intensificació i l'expansió del procés urbà. Consequiència d'això és que la superfície artificial, segons la definició del CORINE Land Cover (CLC), ha passat, entre 1956 i 2006, de l'1\% al 6\% de la superfície insular (Pons, 2003; Blázquez et al., 2008; Pons i Rullan, 2014). Al conjunt de l'Estat espanyol la superfície de sòl artificial era del 2,1\% l'any 2000 (OSE, 2006). Com a característiques principals d'aquest procés d'urbanització hi ha, per un costat, l'atolonització (Rullan, 2002) o urbanització litoral, principalment turística, i, per l'altre, l'expansió de les àrees metropolitanes de cada una de les illes, ja que una explotació intensiva del turisme demana un gran centre de gestió radicat a la capital (Quintana Peñuela, 1978). Mestre (2015) apunta que el creixement desmesurat de la macrocefalia de Palma entre 1960 i 1980 es va veure relativitzat durant els anys posteriors precisament pel pes més gran de l'expansió litoral.

\section{Les illes en la literatura geogràfica}

En treballs recents, els investigadors dels estudis sobre illes han destacat les connotacions negatives del concepte d'insularitat tot apostant pel terme illë̈- 
tat, més precís i complet, atès que inclou tant les connotacions positives com les negatives, les d'obertura o tancament respecte de l'exterior i les referents a fenòmens físics o humans. Baldacchino (2004) ha fet notar com la insularitat s'ha usat habitualment en sentit negatiu, com a tancament enfront del que ve de l'exterior, i aquest negativisme no ha fet justícia al tema dels estudis d'illes, en canvi, la illeïtat representa una aproximació conceptual a les illes que no determina, sinó que perfila i condiciona esdeveniments físics i socials en formes que poden ser de signe diferent.

La utilització del concepte d'illeïtat ens serveix força per descriure i explicar la temàtica analitzada en aquest treball, com és la urbanització i el turisme, ja que, com veurem, per als processos estudiats tant hi intervenen vectors d'obertura com de tancament. El concepte d'illeïtat es deu originàriament a Moles (1982), que la defineix com una funció fenomenològica lligada a tres dimensions: la magnitud de l'illa; la distància d'aquesta a les terres continentals, i el seu caràcter microcòsmic, que li confereix la quantitat de varietat que conté (Barceló, 1997).

La magnitud de les illes es refereix principalment a la seva extensió territorial, però també al desenvolupament costaner que mostra, als recursos de què disposa, a la població, al producte interior brut, etc. La distància a les terres continentals, entesa en termes de connectivitat, representa una segona dimensió de la illeïtat. Molts d'autors, en els seus estudis, apunten a la distància com a factor determinant. És el cas d'Albert Quintana (1972) quan indica que, al segle XIX, la revolució dels transports permet trencar el setge al qual estaven sotmeses les Illes Balears, i que els transports i les comunicacions constitueixen factors bàsics en la configuració humana de les illes, fins al punt que l'anàlisi del trànsit a les Balears donaria una idea bastant correcta de l'isolament real de cadascuna d'elles respecte a les altres. Norberg-Schulz (1980) defineix les illes com a sistemes delimitats per fronteres poroses, oberts tant a esdeveniments positius com negatius, i que les obertures tangibles o els vincles amb l'exterior són els ports i els aeroports, que permeten que tinguin lloc els intercanvis comercials i socials amb el continent. En el mateix sentit, Hay (2006) tracta sobre l'aïllament, la connectivitat de les illes i la permeabilitat dels seus límits com un component important de la illeïtat. Tanmateix, cal tenir en compte que l'aïllament humà, a diferència del que té lloc al medi natural, no és irreversible, sinó que dependrà de l'evolució i de l'estructura dels sistemes de comunicacions i transports, de les característiques de l'economia de les illes, etc. Un exemple clar d'això que diem fou la generalització del trànsit de passatgers per avió, que introduí una nova dimensió que va fer disminuir considerablement el sentit de l'aillament, tot apropant les illes a territoris més llunyans que les costes ibèriques continentals properes, tot acostant-les a l'interior dels continents, especialment l'europeu (Barceló, 1997).

La literatura econòmica i geogràfica molt sovint considera la condició insular com una dificultat per integrar les economies d'aquestes zones en els models financers més internacionalitzats, i atribueix aquest desavantatge a l'increment 
dels costos de transport (Bjarnason, 2010). Aquesta literatura entén la illeïtat com una barrera a la lliure circulació i al comerç derivada de l'aillament, de les dificultats de connectivitat i de la distància fins als continents. Des d'aquesta perspectiva, a les illes sempre caldrà un viatge extra i el canvi d'un tipus de transport a un altre. Això farà que una illa mai pugui competir en igualtat de condicions amb els seus veïns continentals, atès que els costos de vida i de treball que calgui afrontar sempre tendiran a ser superiors als de les àrees continentals properes (Royle, 1989).

La mida de les poblacions insulars, menor que als continents i major, per regla general, a les illes grans que a les petites, influeix en el consum dels seus habitants. Dit altrament: a menys població, més restringits seran els consums (Barceló, 1985). També els recursos naturals seran més limitats a les illes que al continent (Jackson, 2008). La confluència d'aquests condicionants pressuposen una dificultat més gran de les illes per generar economies d'escala (Pintado i Fernández, 2010).

Si tot plegat és cert, la urbanització de les illes s'hauria de veure condicionada per aquesta circumstància. De fet, existeixen dades prèvies a aquest treball que així ho apunten. Les xifres d'OSE (2006) mostren com les illes de l'Estat espanyol presenten els percentatges més baixos de superfície urbanitzada a la franja de $0-2 \mathrm{~km}$ (taula 1). Es tracta d'un fenomen que, com es veurà més endavant, es podria vincular amb la relació entre la magnitud poblacional del territori i la longitud de la línia de costa, superior al continent que a les illes. Rullan (2011) apuntava que la intersecció d'insularitat i estacionalitat ha filtrat la inversió de les grans constructores peninsulars, i això, juntament amb mesures territorials de més importància, explicaria el grau més baix d'urbanització de les Balears.

En una perspectiva contrària, alguns autors han posat l'accent en la capacitat d'atracció de les illes, quasi sempre fent referència a l'avantatge competitiu de les destinacions turístiques insulars en comparació amb les continentals (Baldacchino, 2006; Murray, 2012). Péron (2004) defineix el «mite de l'illa» vinculant-lo a la calma, al sedentarisme, a la relaxació, etc., com un factor d'atracció, en comparació amb el mite de la carretera, que representa el nomadisme, el moviment i l'acció. És a través del turisme (l'activitat econòmica per a la qual les illes solen estar més ben disposades) que han perdut gran part del vector negatiu de la «illeïtat», ja que la insularitat n'ha reduït els efectes, en disminuir la segregació i augmentar els contactes i la informació (Barceló, 1985). Butler (1993) proposa quatre característiques principals per les quals els turistes se senten atrets per les illes: separació física, diferència cultural, clima i medi ambient i autonomia política. Sufrauj (2011) apunta que les illes atreuen el turisme perquè són petites i remotes, i ho corrobora amb proves empíriques. Demostra que la naturalesa de les illes impacta positivament en el desenvolupament de la demanda turística.

Finalment, cal remarcar com els estudis d'illes no són —o no haurien de ser- la mera anàlisi dels esdeveniments ni dels fenòmens que hi tenen lloc, 
Taula 1. Percentatge de superfície artificial de la franja 0-2 km des de la costa. Espanya 2000

\begin{tabular}{lc}
\hline & $\begin{array}{c}\text { Percentatge de superfície artificial de la franja } \\
\text { de } 0-2 \text { km des de la costa }\end{array}$ \\
\hline Costa mediterrània continental & $26,5 \%$ \\
Costa atlàntica sud continental & $19,1 \%$ \\
Costa atlàntica cantàbrica continental & $13,6 \%$ \\
Costes insulars (Balears i Canàries) & $10,9 \%$ \\
\hline
\end{tabular}

Font: Observatorio de la Sostenibilidad en España (2006).

sinó que haurien d'intentar analitzar com la illeïtat, en el seu doble i oposat vector, els condiciona i els perfila. En un sentit de gran abast, els estudis d'illes es poden entendre com la globalització de la localitat (Baldacchino, 2004). A més, es tracta de versions simplificades i exagerades d'aquells mateixos processos evolutius que es donen als continents (Quammen, 1996). No hi ha millor comparació per a una illa que una altra illa, i potser tampoc no hi ha millor comparació per al continent que una illa (Baldacchino, 2004). Grydehøj i Hayward (2014), en el marc d'aplicació d'aquestes teories, han apostat per comparar illes diferents en el seu estudi, i es fan ressò del fet que, tot i la rica literatura teòrica produïda als darrers anys sobre aquesta qüestió, la implementació que se n'ha fet per comprendre les illes a l'actualitat ha estat més aviat pobra. El present treball s'ha realitzat en el marc teòric del que es coneix com estudis d'illes, i pretén aplicar aquestes teories en un cas concret: la urbanització a les Balears.

\section{Hipòtesis i objectius}

A partir del que hem comentat més amunt, plantejam com la illeïtat hauria condicionat, en un doble i contradictori sentit, el procés d'urbanització de les Illes Balears:

1. D'una banda, hauria frenat el procés en funció de la mida de cadascuna de les illes i del grau de connectivitat amb el continent, dues de les tres dimensions del concepte d'illeïtat apuntat.

2. D'altra banda, la illeïtat hauria afavorit el procés d'urbanització a causa de la capacitat d'atracció de les illes (Péron, 2004), i especialment de l'avantatge competitiu que tenen com a destinacions turístiques (Baldacchino, 2006). Així, en incrementar-ne la connectivitat amb el continent, l'atracció de visitants hauria reduït el vector negatiu de la illeïtat $i$, com a conseqüència d'això, hauria augmentat la pressió urbana sobre el litoral.

Per corroborar-ho, ens proposam mesurar, analitzar i explicar com la mida de les illes, la connexió amb els continents i l'activitat turística haurien condicionat els processos d'urbanització de les costes insulars. 


\section{Mètode}

L'àmbit d'estudi del treball són les illes poblades de l'arxipèlag balear ${ }^{1}$. Però, per assolir l'objectiu previst, és de vital importància comparar els factors que s'analitzaran (mida, connectivitat i turisme) en diferents illes. Per aquest motiu, l'estudi no se centra en el conjunt de l'arxipèlag, sinó que treballa cada una de les quatre illes per separat. A més, a fi de confeccionar-ne un model més complet i representatiu, se n'ha ampliat l'àrea d'estudi i també s'hi han inclòs les Canàries².

Per tal de caracteritzar el pes de la illeïtat i l'activitat turística en el procés d'urbanització del litoral, s'ha fet servir el mètode de regressió lineal múltiple (programari SPSS 21) amb un nivell de confiança del 95\%, un mètode força utilitzat en nombrosos treballs semblants (Serra et al., 2008; Serneels i Lambin, 2001), on, com en el cas present, la variable dependent (grau d'urbanització de la costa) presenta valors quantitatius.

La base del model de regressió parteix de les consideracions que ja hem anat desglossant més amunt. Les unitats espacials d'anàlisi han estat cada una de les illes Balears i Canàries i s'han utilitzat una sèrie de variables amb la finalitat d'establir un model que ajudi a explicar el paper de la illeïtat i del turisme en la urbanització de la costa de les illes de l'Estat espanyol. Per simplificar, s'ha utilitzat una única variable explicativa per cada un dels factors derivats de les hipòtesis i dels objectius (mida, connectivitat i activitat turística). Les dades disponibles per a les dues comunitats autònomes insulars són similars i comparables, cosa que permet realitzar-ne un estudi coherent. En el model s'han utilitzat les variables següents:

1. El grau d'urbanització de la costa. Es tracta de la variable que s'inclou dins el model com a dependent. S'ha utilitzat el percentatge d'artificialització de la franja del primer quilòmetre de costa segons les dades del CORINE Land Cover (2006), cosa que permet fer servir la mateixa font per als dos arxipèlags. Aquesta franja d'un quilòmetre ha estat utilitzada en estudis semblants per analitzar el grau de pressió de la urbanització litoral (Pons i Rullan, 2014), i és precisament en aquesta franja on es concentren les zones turístiques de les illes. El terme superficie artificial s'utilitza en la nomencla-

1. Mallorca $\left(3.640,11 \mathrm{~km}^{2}\right.$ i una població de 858.313 habitants l'any 2014), Menorca (695,7 km² i una població de 93.313 habitants l'any 2014$)$, Eivissa $\left(571,6 \mathrm{~km}^{2}\right.$ i una població de 140.271 habitants l'any 2014) i Formentera $\left(83,24 \mathrm{~km}^{2}\right.$ i una població d'11.545 habitants l'any 2014). IBESTAT. <http://ibestat.caib.es/ibestat/page?\&p=inicio\&lang=ca> [consulta: 25 de març de 2017].

2. Tenerife $\left(2.034,3 \mathrm{~km}^{2}\right.$ i una població de 889.936 habitants l'any 2014), Gran Canària (1.560,1 km² i una població de 851.157 habitants l'any 2014), Fuerteventura (1.659,7 $\mathrm{km}^{2} \mathrm{i}$ una població de 106.930 habitants l'any 2014), Lanzarote $\left(845,9 \mathrm{~km}^{2} \mathrm{i}\right.$ una població de 141.940 habitants l'any 2014), Hierro $\left(268,7 \mathrm{~km}^{2}\right.$ i una població de 10.675 habitants l'any 2014), La Gomera (369,7 km² i una població de 20.721 habitants l'any 2014) i La Palma (708,3 km² i una població de 83.456 habitants l'any 2014). ISTAC. <http://www. gobiernodecanarias.org/istac/> [consulta: 25 de març de 2017]. 
tura del CORINE Land Cover (CLC) i es refereix al «teixit urbà continu i discontinu (àrees d'habitatges), industrial, comercial i de transport, carreteres i xarxa de ferrocarril, abocadors i llocs d'extracció, però també àrees verdes urbanes».

2. La magnitud de les illes. L'extensió és un indicador inversament proporcional d'illeïtat, és a dir, les més petites tendran més illeïtat que les més grans. Hi ha illes més illes que d'altres, que tenen més illeïtat, i la mida i la forma en són un indicador (Barceló, 1997). Per treballar aquesta variable s'ha implementat un índex de compacitat per a cadascuna. S'ha calculat un índex que avalua el grau de compacitat per cada illa tot relacionant-ne la superfície amb la de la franja del primer quilòmetre de costa.

$\mathrm{IC}=\mathrm{S} / \mathrm{P}$.

IC: índex de compacitat.

S: superfície de l'illa en quilòmetres quadrats.

P: superfície de la franja d'un quilòmetre de costa en quilòmetres quadrats.

Els índexs de compacitat mesuren la relació entre perímetre i superfície d'un polígon (Richardson, 1961; Osserman, 1978; Maccachren, 1985), però, en aquest cas, s'ha modificat lleugerament canviant el perímetre per la superfície en la franja del primer quilòmetre. L'objectiu d'aquest índex és establir el grau de pressió que existiria sobre la costa en funció de la dimensió i la forma de l'illa. Es parteix de la premissa que la franja de costa és on té lloc la pressió urbanitzadora en aquells espais destinats a la producció turística de sòl i platja (Aguilera-Benavente et al., 2014). Com més gran sigui la superfície d'un territori en relació amb la seva franja de costa, més gran serà la pressió urbanitzadora que s'hi exercirà, sempre considerant-ne tot l'espai isòtrop, amb les mateixes condicions de densitat. Com és conegut, als continents la pressió urbanitzadora serà superior a la de les illes, i a les illes grans aquesta pressió serà superior a la de les més petites (Pons i Rullan, 2014). Aquest índex mesura, per tant, els diferents graus d'illeïtat en funció de la dimensió que presenten i s'inclou dins l'anàlisi de regressió com a variable independent.

3. La connectivitat és inversament proporcional al grau d'illeïtat. Com més connectada estigui una illa amb el continent, més baix serà el seu grau d'illeïtat. La illeïtat disminueix amb l'augment de les connexions, i la freqüència i la capacitat dels transports en són un indicador (Barceló, 1997). Per mesurar la connectivitat de les illes s'ha pres com a variable les entrades de passatgers per ports i aeroports l'any 2006 a partir de les dades disponibles de l'IBESTAT ${ }^{3}$ i l'ISTAC ${ }^{4}$. La xifra d'entrada de passatgers a les illes ha estat tradicionalment un indicador del grau de connectivitat (Seguí i Martínez, 1994; Rullan, 2010). Aquestes xifres s'han relativitzat per la superfície de la franja d'un quilòmetre de costa de cada una de les illes. La variable s'ha inclòs dins l'anàlisi de regressió com la variable independent.

3. <http://ibestat.caib.es/ibestat/inici> [consulta: 3/01/2017].

4. <http://www.gobiernodecanarias.org/istac/> [consulta: 3/01/2017]. 
4. L'activitat turística fa incrementar la connectivitat $i$, en conseqüència, disminueix la illeïtat. És allò que hem denominat factor d'atracció. Atès que l'especialització turística de les Balears i de les Canàries, en el marc del capitalisme global, és el factor que ha permès reduir els efectes econòmics de la insularitat tot impulsant la millora de la connectivitat amb el continent, s'hi ha introduït una variable relacionada amb l'activitat turística. S'han utilitzat les dades de places turístiques disponibles per a cada una de les illes en els serveis d'estadística de les dues comunitats autònomes en refer a l'any 2010. Per comprendre la geografia de les regions turístiques és essencial realitzar un enfocament de l'oferta, i l'allotjament és un dels elements clau de la indústria turística (Ioannides i Debbage, 1998). Aquestes xifres s'han relativitzat per la superfície de la franja d'un quilòmetre de costa de cada una de les illes. D'aquesta manera es disposa de l'indicador més important per mesurar la pressió que suposa el sector turístic a la franja costanera. La variable s'ha inclòs dins l'anàlisi de regressió com a variable independent.

5. Finalment, i per acabar de configurar el model, s'ha introduït com a variable el grau d'estacionalitat. La diferència d'estacionalitat entre les Balears i les Canàries requeria un factor de correcció. Les primeres presenten un model estacional molt marcat, amb una temporada alta durant els mesos d'estiu i un descens important de l'activitat a l'hivern. En canvi, les segones, gràcies al seu clima subtropical, tenen un model turístic desestacionalitzat. S'ha calculat el grau d'estacionalitat per al període 2008-2014 a partir de l'índex de Gini (López i López, 2006; Duro i Farré, 2015) de visitants mensuals arribats a cada una de les illes (fonts IBESTAT i ISTAC). Aquest indicador pren valors que poden oscil-lar entre el 0 i l'1. El 0 indica l'absència d'estacionalitat i l'1, la màxima estacionalitat. Aquesta variable s'ha inclòs dins l'anàlisi de regressió com a variable independent.

Lògicament, s'haurien pogut escollir més variables independents que haurien ajudat a caracteritzar el model de regressió, perquè n'hi ha més que influeixen en el grau d'urbanització de la franja litoral, però s'han triat estrictament aquelles que ajuden a corroborar les dues hipòtesis plantejades i que deriven de la consideració del concepte d'illeïtat estudiat (Moles, 1982; Baldacchino, 2006; Péron, 2004).

Una manera d'explicar aquest model seria mitjançant la utilització de cercles de mida diferent. Un cercle petit podria representar una illa petita i un cercle gran en podria representar una de més gran o bé el continent. El perímetre dels cercles es podria assimilar a la línia de la costa. Si partim de la premissa que la franja de costa és on té lloc la pressió urbanitzadora més forta en aquells espais destinats a la producció turística de sol i platja, aleshores, amb les mateixes condicions de densitat en els dos cercles, la pressió sobre el perímetre serà més elevada en el cercle més gran, perquè la relació entre la superfície $\mathrm{i}$ la longitud de perímetre és superior. Si prenem com a exemple el gràfic de la figura 1, el cercle gran, de 10 centímetres de diàmetre, tendria una pressió de 
Figura 1. Model d'illeïtat. Relació de mida de cercle i perímetre
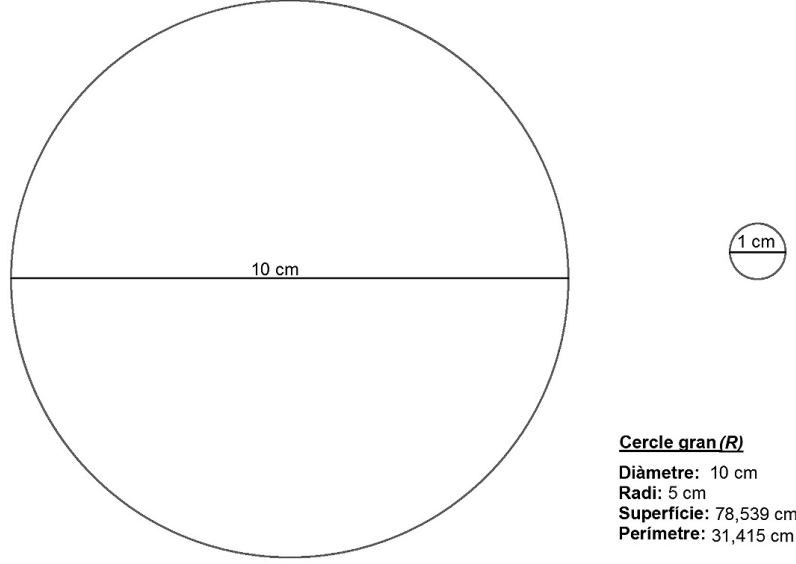

Diàmetre: $10 \mathrm{~cm}$

Radi: $5 \mathrm{~cm}$

Superficie: $78,539 \mathrm{~cm}^{2}$

Cercle petit $(r)$

Diàmetre: $1 \mathrm{~cm}$

Radi: $0,5 \mathrm{~cm}$

Superfície: $0,7853 \mathrm{~cm}^{2}$
Perimetre: $3,1415 \mathrm{~cm}$

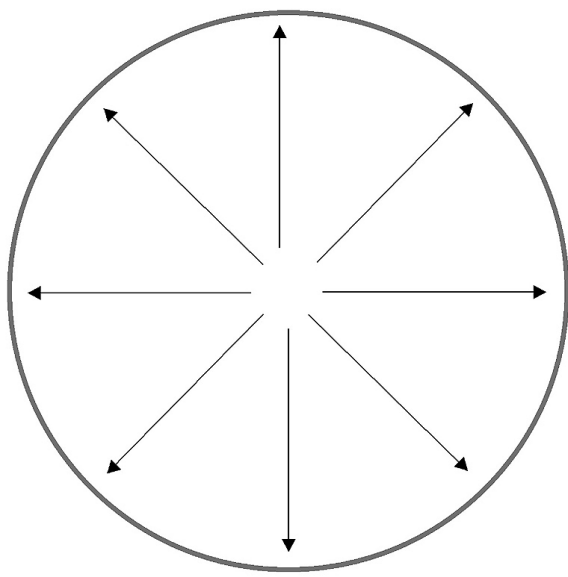

Cercle gran $(R)$

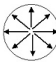

Superficie / Perímetre:

Cercle petit $(r)$

$2,50 \mathrm{~cm}^{2} / \mathrm{cm}$ de perimetre $0,25 \mathrm{~cm}^{2} / \mathrm{cm}$ de perimetre

Font: elaboració pròpia.

2,5 $\mathrm{cm}^{2}$ per cada centímetre de perímetre, en canvi el cercle petit tendria una pressió de $0,25 \mathrm{~cm}^{2}$.

Per tant, amb les mateixes condicions de densitat de població, la pressió sobre el litoral a les illes sempre hauria de ser inferior a la del continent, on la superfície més gran sempre implica volums superiors de població per longitud de costa.

A fi d'incrementar la pressió sobre el perímetre del cercle petit es requerirà una densitat superior, que es pot aconseguir amb una connectivitat més elevada amb el cercle gros. A mesura que el cercle gros passa part de la seva pressió al cercle petit, s'anirà incrementant la pressió sobre el perímetre d'aquest.

Les illes podran incrementar la seva pressió sobre la costa si augmenten la connexió amb el continent en termes de turistes, fluxos de recursos, etc. Com 
més connectades estiguin al continent, més pressió hi haurà sobre la costa, fins al punt que una illa que es connectés totalment amb el continent passaria a tenir una pressió pròpia i, per tant, podria arribar a mostrar percentatges d'urbanització semblants als del continent.

\section{Resultats}

La urbanització del litoral a les Balears i a les Canàries s'hauria vist condicionada per dues forces que han actuat en sentits oposats. Per un costat, la illeïtat, entesa en termes de dimensió de les illes i desconnexió del continent, que hauria actuat com a fre, i, per l'altre, el turisme, que ha esdevingut un factor impulsor del procés.

Els resultats del model de regressió múltiple implementat per a les Balears i les Canàries presenten uns graus de correlació clarament significatius, tal com demostren les estadístiques (taula 2). Com més petites i menys connectades estan les illes amb l'exterior, menor és el grau d'urbanització de la seva franja costanera (taula 3 i figura 2).

Taula 2. Dades estadístiques del model de regressió múltiple. Urbanització de la franja d'un quilòmetre de costa en funció de la illeïtat i de l'activitat turística. Balears i Canàries (20062010)

\begin{tabular}{ll}
\hline Estadístiques de la regressió & \\
\hline Coeficient de correlació múltiple $(R)$ & 0,97013121 \\
Coeficient de determinació $R^{2}$ & 0,94115456 \\
$R^{2}$ ajustat & 0,90192426 \\
Error típic & 0,02930159 \\
\hline
\end{tabular}

Font: elaboració pròpia.

Taula 3. Matriu de correlacions del model de regressió múltiple. Urbanització de la franja d'un quilòmetre de costa en funció de la illeïtat i de l'activitat turística. Balears i Canàries (2006-2010)

\begin{tabular}{lccccc}
\hline & $\begin{array}{c}\text { Percentatge } \\
\text { d'urbanització } \\
\text { d'1 km de costa } \\
(\mathbf{2 0 0 6 )}\end{array}$ & $\begin{array}{c}\text { Índex de } \\
\text { compacitat }\end{array}$ & $\begin{array}{c}\text { Places turístiques / } \\
\mathrm{km}^{2} \mathrm{en} \text { 1 km de } \\
\text { costa (2010) }\end{array}$ & $\begin{array}{c}\text { Arribades a ports } \\
\text { i aeroports / km² } \\
\text { en 1 km de costa } \\
\text { (2006) }\end{array}$ & $\begin{array}{c}\text { Índex } \\
\text { d'estacionalitat }\end{array}$ \\
\hline $\begin{array}{l}\text { Percentatge d'urbanització } \\
\text { en 1 km de costa (2006) }\end{array}$ & 1,000 & 0,719 & 0,953 & 0,881 & $-0,097$ \\
Índex de compacitat & 0,719 & 1,000 & 0,693 & 0,726 & $-0,417$ \\
$\begin{array}{l}\text { Places turístiques / km² } \\
\text { en 1 km de costa (2010) }\end{array}$ & 0,953 & 0,693 & 1,000 & 0,952 & 0,061 \\
$\begin{array}{l}\text { Arribades a ports i aeroports / } \\
\text { km² en 1 km de costa (2006) }\end{array}$ & 0,881 & 0,726 & 0,952 & 1,000 & 0,039 \\
Índex d'estacionalitat & $-0,097$ & $-0,417$ & 0,061 & 0,039 & 1,000 \\
\hline
\end{tabular}

Font: elaboració pròpia. 
Figura 2. Relació de les variables independents amb la variable dependent. Model de regressió múltiple. Urbanització de la franja del primer quilòmetre de costa en funció de la illeïtat i de l' activitat turística. Balears i Canàries (2006-2010)
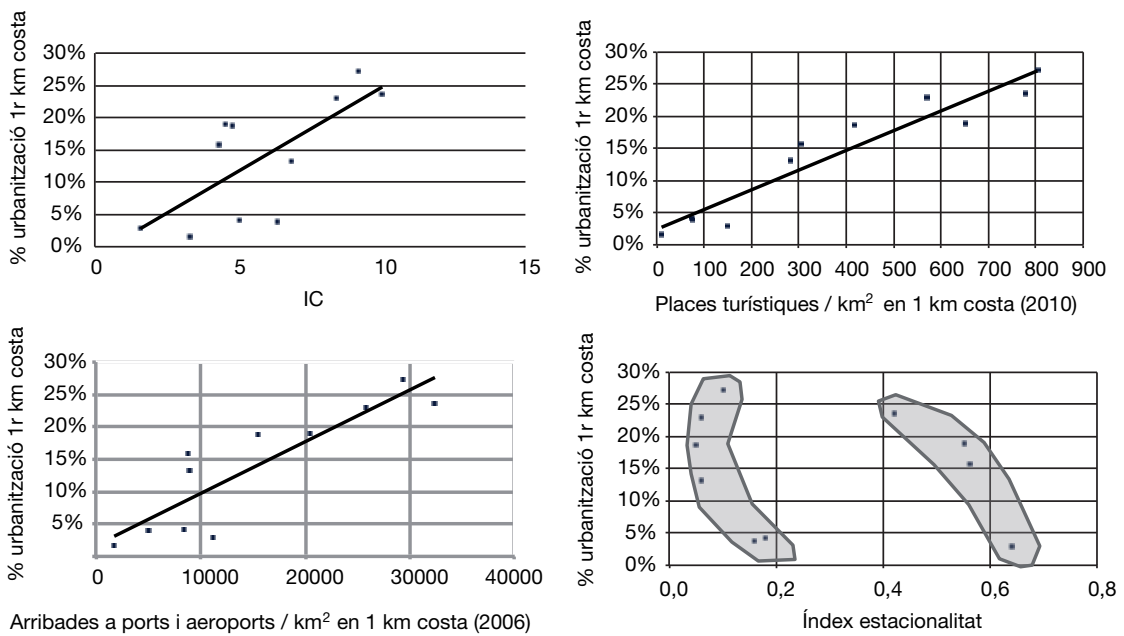

Font: elaboració pròpia.

Les illes que presenten unes xifres més elevades de compacitat, les més grans - Mallorca a les Balears o Tenerife i Gran Canària a les Canàries (taula 4)_, per regla general, tenen la franja costanera més urbanitzada. El coeficient de correlació de Pearson entre les dues variables — compacitat i urbanització de la costa— és de 0,719 .

Les illes més connectades amb l'exterior, aquelles que registren més arribades per port i aeroport -Mallorca i Eivissa a les Balears i Gran Canaria i Tenerife a les Canàries (taula 4) — són també les que tenen una pressió més elevada de la urbanització per superfície a la franja costanera d'un quilòmetre. El coeficient de correlació d'aquestes variables és de 0,881.

D'altra banda, l'activitat turística ha contribuït a incrementar-ne la connectivitat $i$, com a conseqüència, a reduir-ne l'aïllament. Existeix una elevada correlació, pràcticament perfecta, entre les arribades a ports i aeroports i les places turístiques $(0,952)$. Les illes més connectades són també les que n'ofereixen més (Mallorca, Eivissa, Gran Canaria i Tenerife). A la vegada, també existeix una correlació molt elevada entre les places turístiques i el percentatge de superfície urbanitzada de la costa $(0,953)$, cosa que permetria deduir que el turisme ha contribuït a incrementar-lo de manera determinant.

L'índex d'estacionalitat, en canvi, presenta una relació inversament proporcional, és a dir, a menys estacionalitat més urbanització del litoral. No obstant això, aquesta vegada el coeficient de correlació és pràcticament nul $(-0,097)$, perquè es comparen les Balears i les Canàries amb dos models d'estacionalitat completament diferents. Les primeres tenen una estacionalitat més elevada, 
Taula 4. Resultats del model de regressió múltiple. Urbanització de la franja del primer quilòmetre de costa en funció de la illeïtat i de l'activitat turística. Balears i Canàries (2006-2010).

\begin{tabular}{|c|c|c|c|c|c|c|c|}
\hline Illa & $\begin{array}{l}\text { Percentatge } \\
\text { d'urbanització } \\
\text { en } 1 \text { km de } \\
\text { costa (2006) }\end{array}$ & $\begin{array}{l}\text { Índex de } \\
\text { compacitat }\end{array}$ & $\begin{array}{c}\text { Arribades } \\
\text { a ports i } \\
\text { aeroports / km² } \\
\text { en } 1 \mathrm{~km} \mathrm{de} \\
\text { costa }(2006)\end{array}$ & $\begin{array}{c}\text { Places } \\
2 \text { turístiques / } \\
\mathrm{km}^{2} \text { en } 1 \mathrm{~km} \text { de } \\
\text { costa }(2010)\end{array}$ & $\begin{array}{c}\text { Índex } \\
\text { d'estacionalitat }\end{array}$ & $\begin{array}{l}\text { Pronòstic de } \\
\text { regressió }\end{array}$ & Error \\
\hline Eivissa & $18,92 \%$ & 4,53 & $20.480,40$ & 651,12 & 0,55 & $21,75 \%$ & $-2,83 \%$ \\
\hline Formentera & $2,86 \%$ & 1,59 & $11.198,05$ & 148,46 & 0,64 & $3,30 \%$ & $-0,44 \%$ \\
\hline Fuerteventura & $13,20 \%$ & 6,84 & $8.957,63$ & 280,85 & 0,06 & $13,35 \%$ & $-0,15 \%$ \\
\hline Gran Canària & $27,29 \%$ & 9,17 & $29.288,05$ & 803,37 & 0,10 & $28,44 \%$ & $-1,15 \%$ \\
\hline Hierro & $1,56 \%$ & 3,32 & $1.754,64$ & 10,33 & - & $3,77 \%$ & $-2,22 \%$ \\
\hline La Gomera & $4,18 \%$ & 5,02 & $8.455,95$ & 72,56 & 0,18 & $4,13 \%$ & $0,04 \%$ \\
\hline La Palma & $3,90 \%$ & 6,36 & $4.986,37$ & 75,88 & 0,16 & $5,51 \%$ & $-1,61 \%$ \\
\hline Lanzarote & $18,69 \%$ & 4,78 & $15.539,96$ & 418,42 & 0,05 & $16,91 \%$ & $1,79 \%$ \\
\hline Mallorca & $23,57 \%$ & 10,01 & $32.382,68$ & 777,52 & 0,42 & $24,53 \%$ & $-0,96 \%$ \\
\hline Menorca & $15,81 \%$ & 4,30 & $8.806,17$ & 303,53 & 0,56 & $11,02 \%$ & $4,79 \%$ \\
\hline Tenerife & $22,93 \%$ & 8,39 & $25.773,15$ & 569,69 & 0,06 & $20,19 \%$ & $2,73 \%$ \\
\hline
\end{tabular}

Font: elaboració pròpia.

basada en un model turístic de sol i platja propi de l'àrea mediterrània, amb una temporada alta durant els mesos d'estiu i en canvi amb molt poca activitat turística durant l'hivern. Les segones, en canvi, amb un clima subtropical, mostren una distribució més homogènia de visitants al llarg de l'any. La relació funciona dins de cada arxipèlag: el coeficient de correlació de Pearson de les Balears és de $-0,895$, mentre que el de les Canàries és de $-0,715$, però no entre arxipèlags. Es tracta d'una variable que ens ha permès corregir les diferències existents entre els dos conjunts i ajustar el grau d'urbanització dins de cadascun.

Els resultats de la implementació del model de regressió mostren com les variables independents estudiades expliquen de manera important el grau d'urbanització que té lloc a la costa de les illes. A la taula 4 s'inclouen els valors de cada una de les variables diferenciades per illes i els resultats pronosticats amb el model de regressió per cada una de les unitats d'anàlisi, com també el percentatge d'error. D'aquesta manera es poden apreciar millor les diferències entre els valors reals de la variable dependent i els observats en el model de regressió lineal múltiple aplicat. S'hi introdueix, així mateix, un diagrama de dispersió on es pot observar el grau d'ajustament dels valors pronosticats i dels reals.

L'anàlisi de regressió múltiple ha servit per caracteritzar el fenomen estudiat i per determinar la importància de cada un dels factors analitzats (dimensió de les illes, connexió amb el continent, activitat turística reglada i estacionalitat). Les xifres pronosticades (taula 4 i figura 3) s'ajusten de manera important a les xifres reals d'urbanització, cosa que demostra que les variables estudiades 
Figura 3. Relació dels valors reals dels percentatges d'urbanització del primer quilòmetre de costa i valors pronosticats a la regressió lineal múltiple en funció de la illeïtat i de l'activitat turística. Balears i Canàries (2006-2010)

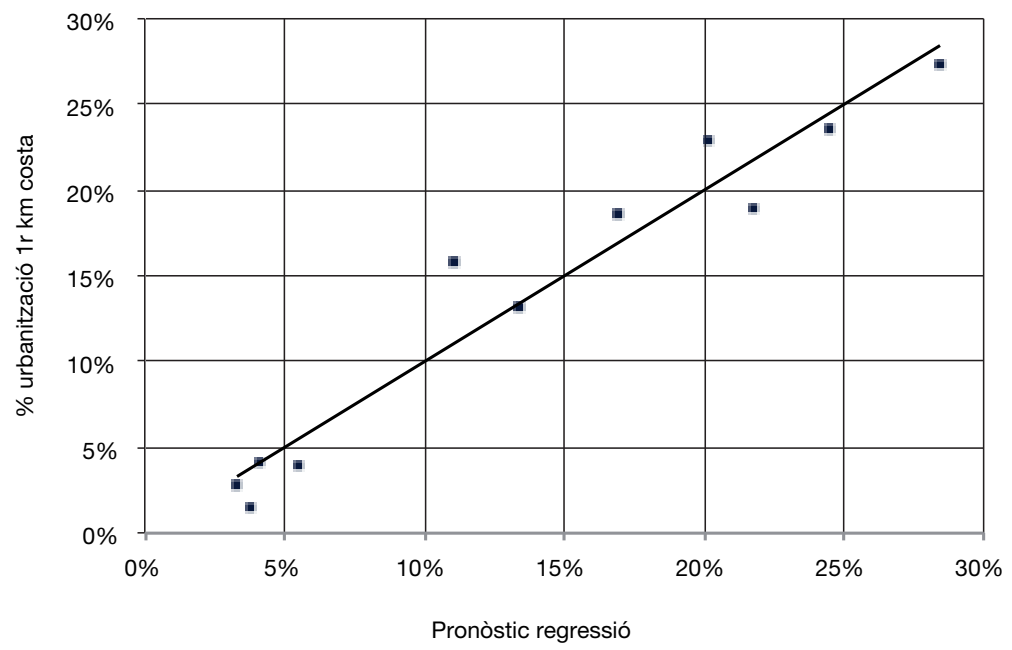

Font: elaboració pròpia.

expliquen aquest procés per als casos estudiats: les illes Balears i les Canàries. Els coeficients de correlació múltiple, el de determinació i el de determinació ajustat presenten valors superiors a 0,9, de manera que el grau de significació és molt alt. En la majoria d'exemples, la desviació dels percentatges d'urbanització reals i observats es desvien només uns quants punts percentuals.

El cas que presenta més desviació és l'illa de Menorca, en la qual els valors esperats de percentatge de superfície urbanitzada de la franja del primer quilòmetre de costa se separen 4,79 punts del valor observat: $11,02 \%$ enfront del 15,81\%. Aquesta diferència s'explicaria per diferents motius, per exemple: Menorca presenta l'eclosió de l'activitat turística en el que es coneix com a segon boom de visitants a les Illes Balears (Pons et al., 2014), i en aquest període dominen els apartaments com a tipologia d'instal.lacions turístiques, un model d'establiment molt més extensiu. A part d'això, a Menorca també són molt importants les àrees litorals urbanitzades destinades a turisme residencial, grans extensions dominades per habitatges unifamiliars aïllats. Això és molt evident, per exemple, al sud de Maó, a les zones turístiques de Sant Lluís, al nord, a les de Mercadal i també a la costa oest de Ciutadella. Aquest tipus d'urbanització costanera de Menorca afavoreix una alta ocupació amb unes densitats molt baixes. Si s'eliminés Menorca de l'anàlisi de regressió, els resultats encara s'ajustarien molt més i mostrarien uns valors de correlació molt més alts: el coeficient de correlació múltiple seria un 0,995; el coeficient de determinació, un 0,990, i el coeficient de determinació ajustat, un 0,983. 
En qualsevol cas, la regressió treballada no pretén ser un model que expliqui completament el grau d'urbanització de les franges costaneres insulars, sinó que es tracta d'un model per ajudar a entendre el paper que la illeïtat, entesa en termes de connectivitat i dimensió de les illes, i les places turístiques han tengut en el grau d'urbanització costanera de les Illes Balears. A part de les variables utilitzades n'hi ha unes altres que expliquen el grau d'urbanització present a les costes insulars. De fet, cada illa mostra unes característiques pròpies que escapen al model, així, per exemple, a Menorca té un pes determinant la urbanització extensiva residencial i a Formentera destaquen les estades turístiques d'un sol dia.

\section{Discussió i explicació dels resultats}

La illeïtat, entesa tant en termes de dimensió de les illes com de desconnexió respecte al continent, és un factor que ha condicionat el menor grau d'urbanització de la franja costanera de les Balears i les Canàries en relació amb altres regions continentals (Pons i Rullan, 2014). Ara bé, aquesta illeïtat s'ha vist contrarestada com a conseqüència de la integració de l'economia insular en el marc del capitalisme global, com a destí turístic de masses. L'activitat turística ha augmentat la connectivitat dels dos arxipèlags amb el continent i n'ha reduït l'isolament. Una conseqüència d'això ha estat l'increment de la pressió sobre el litoral que s'ha urbanitzat més intensament, tot i que les xifres que hi fan referència queden sempre per sota de les del continent.

En el present treball s'ha implementat un model de regressió per explicar com illeïtat i turisme haurien condicionat el grau d'urbanització de la franja costanera de les Balears i les Canàries.

La dimensió o la magnitud de les illes és un factor que correlaciona positivament amb el grau de pressió sobre la costa en forma d'urbanització. Com més gran és una illa, menys illa és o, dit d'una altra manera, més petita és la seva illeïtat (Barceló, 1997) i més gran la pressió urbanitzadora sobre la costa. El coeficient de correlació és de 0,719 entre l'índex de compacitat (relació entre la superfície en el primer quilòmetre de costa i la superfície total de l'illa) i el percentatge de superfície urbanitzada a la franja del primer quilòmetre. Les illes més grans, com ara Mallorca a les Balears o Tenerife i Gran Canaria a les Canàries, presenten uns valors d'urbanització del primer quilòmetre de costa superiors, i també un índex més elevat de compacitat. D’altra banda, les illes més petites experimenten menys pressió urbanitzadora sobre la costa, és a dir, presenten unes relacions inferiors de superfície total de l'illa respecte a la franja del primer quilòmetre de costa. El continent, en canvi, per la mateixa raó, tendria una pressió més gran sobre la franja costanera (Pons i Rullan, 2014). En tot cas, això serà sempre així en un espai isòtrop, amb una mateixa densitat de població, atès que és la població la que exerceix la pressió sobre la franja litoral. L'extensió de les poblacions insulars, més petita que la dels continents i més gran, per regla general, a les illes majors que a les illes menors, influeix en el consum. És a dir, com menys població hi hagi, més restringits seran 
els consums (Barceló, 1985), i això és extrapolable al consum de territori, al procés d'urbanització de la costa: com menys població hi hagi, menor pressió urbanitzadora s'exercirà sobre el litoral.

El segon factor que explica el grau d'illeïtat és la desconnexió respecte del continent. Les limitacions en el transport afecten qüestions econòmiques $\mathrm{i}$ socials, inclòs el turisme (Baldacchino, 2004). La illeïtat es pot modificar, de fet disminueix, a mesura que augmenten les comunicacions i fins i tot es pot arribar a perdre (Barceló, 1997). La distància humana entre el continent i les illes és un factor que s'explica per la duració del viatge, el cost, la freqüència i la capacitat de transport. Així, l'ús de l'avió va fer disminuir considerablement l'aïllament $\mathrm{i}$ acostà les illes al continent, fins al punt que les distàncies i l'efecte de la barrera marítima es varen reduir (Péron, 2004). El nombre de passatgers, utilitzat com a valor de connectivitat en l'anàlisi de regressió, correlaciona positivament amb la pressió urbanitzadora sobre el seu litoral. En aquest cas, el coeficient de correlació assoleix un valor de 0,881 , superior al que es donava en el factor de magnitud. Les illes com ara Mallorca (32.382,68 arribades l'any 2010 per $\mathrm{km}^{2}$ en la franja d'un quilòmetre de costa), Gran Canària $(29.288,05)$, Tenerife $(25.773,15)$ o Eivissa $(20.480,40)$, amb una connectivitat més elevada, mostren uns percentatges superiors d'urbanització de la franja litoral.

La illeïtat com a fre de la urbanització és un aspecte que queda ressaltat en altres estudis que demostren que el grau d'urbanització del litoral de les Illes Balears és inferior al d'altres regions continentals de la costa mediterrània europea occidental (Pons i Rullan, 2014; Observatorio de la Sostenibilidad en España, 2006). La condició insular ha retardat l'entrada de les illes en els circuits internacionals de turisme, a causa de la necessitat de servir-se d'uns mitjans de transport que comporten uns costos elevats. Així, el menor grau d'urbanització de les Illes Balears s'ha de valorar en comparació amb regions continentals del mateix àmbit que tenen una història turística més llarga.

A part de la dimensió i de la connectivitat, hi ha uns altres factors que haurien contribuït al fet que la urbanització del litoral de les Illes Balears mostri una taxa més baixa, però, en qualsevol cas, no han estat tan decisius. Un d'aquests factors és, per exemple, les mesures territorials, que han estat més contundents a les illes que al continent (Rullan, 2011). Cal tenir en compte que hi ha estudis que demostren que les illes de l'Estat espanyol disposen d'uns percentatges més elevats de territori protegit (González, 2003). Aquest fet té diverses explicacions possibles: els conflictes socials, la pressió dels lobbys hotelers (Murray, 2012; Buades, 2006) o l'escassesa de recursos naturals (energia o aigua) que implica l'ailllament i la desconnexió (Jackson, 2008). Però, als anys noranta, quan els governs autonòmics comencen a aplicar les mesures de protecció territorial, el grau d'urbanització a les illes Balears i a les Canàries ja és inferior al dels veïns continentals. L'any 1990, el percentatge d'urbanització de la franja del primer quilòmetre de costa és de l'11,2\% a les illes Balears i a les Canàries, enfront del 28,2\% de la costa continental mediterrània espanyola (Pons i Rullan, 2014). 
Altrament, l'activitat turística ha estat el factor desencadenant de l'increment de la connectivitat i, per tant, de la disminució de la illeïtat. La mateixa illeïtat, o condició insular, hauria estat la impulsora del procés d'urbanització. D'una banda, el gen insular hauria frenat la urbanització com a conseqüència de la desconnexió o de la dimensió de les illes, però, d'altra banda, les condicions que es van donar durant la segona meitat del segle XX haurien afavorit el desenvolupament de la l'activitat turística, cosa que en va impulsar la urbanització. Les Balears, pel fet de ser illes, disposen de molt de litoral i d'un avantatge comparatiu respecte a unes altres destinacions turístiques. El mite de l'illa (Péron, 2004) està vinculat a la calma, al sedentarisme, a la relaxació, etc., en comparació amb el mite de la carretera, que representa el nomadisme, el moviment i l'acció. En el marc de l'economia global, aquests condicionants del turisme de masses de sol i platja, d'una posició estratègica avantatjosa (clima adequat i proximitat al centre econòmic d'Europa) i del desenvolupament de l'aviació, han estat els desencadenants de la urbanització del litoral illenc. Hi ha uns altres autors que parlen també d'aquest avantatge competitiu de les illes com a destinacions turístiques (Baldacchino, 2006; Murray, 2012). Baum (1997) ressalta que hi ha alguna cosa especial i diferent en el fet d'agafar un avió i anar a una destinació turística insular. Un cop allà, el sentiment de separació respecte del continent és també un atribut físic i psicològic d'unes vacances reeixides. Si el que busquen els visitants és sol, arena i mar, moltes illes d'aigües temperades n'estan plenes. Hi ha 36 petits estats insulars i territoris en el món, amb poblacions de menys d'un milió d'habitants i amb superfícies inferiors als $5.000 \mathrm{~km}^{2}$, que mostren el nivell més alt de penetració del turisme (McElroy, 2006; McElroy i Hamma, 2010). Uns altres autors han relacionat el poder d'atracció de les illes amb una maledicció, perquè en els darrers cinquanta anys cap altra indústria ha estat tan lucrativa i, a la vegada, tan intrusiva. El turisme ha salvat les illes i les ha condemnades (Fischer, 2012).

La correlació entre places turístiques i urbanització de la costa és la més alta en l'anàlisi de regressió realitzat $(0,953)$. A més, existeix una forta correlació entre places turístiques i passatgers arribats $(0,952)$, cosa que podria demostrar que la connectivitat s'incrementa a mesura que augmenten les places per als visitants, i viceversa. Des de la dècada de 1950, l'activitat turística ha contribuït a incrementar la connectivitat de les Balears amb el continent (Pons et al., 2014) i, com a conseqüència, n'ha reduït la illeïtat. El resultat d'aquest procés ha estat una pressió urbanitzadora més elevada sobre les zones litorals, que, no obstant això, continuen mostrant percentatges d'urbanització inferiors als del continent.

A les Illes Balears, a part del fet insular, hi ha unes altres variables que hi han facilitat el desenvolupament del turisme de masses: un clima mediterrani, adequat per practicar-hi el turisme de sol i platja, i un marc jurídic i econòmic favorable. Però, sobretot, una innovació tècnica com l'aviació comercial, que ha fet incrementar la connectivitat de les illes amb el continent $i$, en conseqüència, de manera paradoxal, n'ha reduït la illeïtat. 
Per altra part, el turisme és una activitat peculiar perquè els espais de producció i de consum coincideixen, de manera que la principal conseqüència territorial a les destinacions turístiques és la producció d'espais urbans destinats als visitants. En aquest sentit, les destinacions turístiques insulars no en són una excepció i, per tant, veuen incrementada la seva urbanització.

\section{Conclusions}

A la vista dels resultats de l'estudi, es pot concloure que la illeïtat ha condicionat doblement el procés d'urbanització o d'artificialització del sòl a les Illes Balears. Tal com es plantejava a les dues hipòtesis de partida, la desconnexió respecte al continent i la reduïda dimensió que presenten han suposat un fre per a l'artificialització del litoral de les illes. En canvi, el turisme, considerat un avantatge competitiu, l'ha impulsada. Els resultats de l'anàlisi de regressió implementada per a les illes dels arxipèlags balear i canari així ho demostren.

Les illes més grans, com ara Mallorca, a les Balears, o Tenerife i Gran Canària, a les Canàries, i les més ben comunicades amb l'exterior, com ara Mallorca i Eivissa, a les Balears, i Gran Canària i Tenerife, a les Canàries, són les que han assolit uns graus més elevats d'artificialització de la seva franja litoral. Per la mateixa raó, el continent exercirà una major pressió sobre la seva franja costanera, tal com demostren les xifres d'estudis previs sobre la superfície urbanitzada al litoral.

D'altra banda, la capacitat d'atracció de les illes com a destinacions turístiques competitives n'ha impulsat l'activitat, i la conseqüència territorial principal ha estat la producció d'espais urbans turístics, és a dir, la illeïtat ha empès la producció d'urbanització turística al litoral. Aquelles illes on l'activitat turística té un pes més fort, amb més places per acollir els visitants, com ara Tenerife o Gran Canària, a les Canàries, i Mallorca i Eivissa, a les Balears, són també les que tenen el litoral més urbanitzat. El turisme ha incrementat la connectivitat de les illes i la pressió urbanitzadora sobre les franges litorals, les quals, no obstant això, continuen tenint un grau d'urbanització inferior al del continent.

\section{Referències bibliogràfiques}

Aguilera-Benavente, F.; Botequilha-Leitao, A. i Díaz-Varela, E. (2014). "Detecting multi-scale urban growth patterns and processes in the Algarve region (Southern Portugal)». Applied Geography, 53, 234-245.

<http://dx.doi.org/10.1016/j.apgeog.2014.06.019>

AlmeIdA, F. i CORTÉS, R. (2011). «Transformaciones urbanísticas y territoriales en la Costa del Sol Oriental: ¿Otra Costa del Sol Occidental?». A: AGE. Urbanismo expansivo de la utopia a la realidad. Universitat d'Alacant: Vicente Gonzálvez Pérez, José Antonio Marco Molina. XXII Congreso de Geógrafos Españoles, 15-28.

Baldacchino, G. (2004). "The coming of age of island studies». Tijdschrift voor Economische en Sociale Geografie, 95 (3), 272-283.

<https://doi.org/10.1111/j.1467-9663.2004.00307.x> 
- (2006). "Warm versus Cold Water Island Tourism: A Review of Policy Implications». Island Studies Journal, 1 (2), 183-200.

BARCEló, B. (1985). «Introducció a la nisologia». A: À. d. BArCelona (ed.). I Conferència Econòmica de la Mediterrrània Nord-Occidental. Barcelona: Fundació del Congrés de Cultura Catalana, p. 2071.

- (1997). «Illes, illeïtat i insularitat: Les Illes Balears, per exemple». Comunicacions dels membres de la Secció de Filosofia i Ciències Socials XXII. Barcelona: Institut d'Estudis Catalans, 111-127.

BAUM, T. G. (1997). «The fascination of islands: A tourist perspective». A: LOCKHART, G. G. i Drakakis-Smith, D. Island Tourism: Problems and Perspectives. Londres: Mansell, 21-35.

BJARNASON, D. (2010). «Island Connections: Icelandic Spatiality in the Wake of Worldly Linkages». Island Studies Journal, 5 (2), 217-236.

BuAdes, J. (2006). Exportando paraísos: La colonización turística del planeta. Palma: La Lucerna.

Burak, S.; Dogan, E. i Gazioglu, C. (2004). «Impact of urbanization and tourism on coastal environment». Ocean \& Coastal Management, 47, 515-527. $<$ https://doi.org/10.1016/j.ocecoaman.2004.07.007>

Burriel, E. (2016). «Empty urbanism: The bursting of the Spanish housing bubble». Urban Research \& Practice, 9, 1-22. <https://doi.org/10.1080/17535069.2015.1110196>

Butler, R. W. (1993). "Tourism development and small islands: Past influences and future directions». A: LochHart, D. G.; Drakakis-Smith, D. i Schembri, J. A. The Development Process in Small Island States. Londres: Routledge, 71-79.

CAPEL, H. (2003) «A modo de introducción: Los problemas de las ciudades. Urbs, Civitas y Polis». A: CAPEL, H. Mediterráneo económico: Ciudades, arquitectura y espacio urbano. Vol. 3 (Feb. 2003). Almeria: Publicaciones de Cajamar, 9-22.

Carrascal, E. i Pérez Villegas, G. (1998). "Ocupación territorial y deterioro ambiental ocasionado por la expansión urbano-turística en Acapulco, Guerrero». Investigaciones Geográficas, 37, 111-124.

Cuadrado, S.; Durà, A. i Estalella, H. (2006). «La transformación de los asentamientos en el litoral turístico catalán: Análisis cartográfico y estadístico del Alt Empordà». Investigaciones Geográficas, 40, 159-182. <http://dx.doi.org/10.14198/INGEO2006.40.08>

DematTEIS, G. (1998). «Suburbanización y periurbanización: Ciudades anglosajonas y ciudades latinas (English cities and latin cities)». A: Monclús, F. J. (ed.). La ciudad dispersa: Suburbanización y nuevas periferias. Barcelona: Centre de Cultura Contemporània de Barcelona, 17-33.

Duro, J. A. i FARRÉ, F. X. (2015). «Estacionalidad turística en las provincias españolas: Medición y análisis». Cuadernos de Turismo, 36, 157-174. <https://doi.org/10.6018/turismo.36.230921>

Emmi, P. C. i Santigosa, M. A. (1989). «Urban development, land use planning and political change: The case of Costa Brava, Spain». Land Use Policy, 103-120. <https://doi.org/10.1016/0264-8377(89)90037-9>

Ezquerra, A.; Moreno, E.; Otero, I. i Urbano, J. (1999). «Evaluación de cambios de cobertura del suelo en la Costa Valenciana 1975-1991». A: VIII Congreso Nacional de Teledetección. Albacete, España, 1999. Albacete: Santiago Castaño Fernández y Antonio Quintanilla Rodenas, 15-18.

FISCHER, S. R. (2012). Islands: From Atlantis to Zanzibar. Londres: Reaction Books. 
García-Ayllón, S. (2015). «La Manga case study: Consequences from short-term urban planning in a tourism mass destiny of the Spanish Mediterranean coast». Cities, 43, 141-151. <https://doi.org/10.1016/j.cities.2014.12.001>

GONZÁLEZ, A. i SOBRAL, S. (2011). «El desarrollo urbano-turístico del municipio de Yaiza, Lanzarote: Un ejemplo de crecimiento expansivo». A: AGE. Urbanismo expansivo de la utopía a la realidad. Universitat d'Alacant: Vicente Gonzálvez Pérez, Juan Antonio Marco Molina. XXII Congreso de Geógrafos Españoles, 319-330.

GONZÁlEZ, M. (2003). «El territorio protegido en las comunidades autónomas». Revista Galega de Economía, 12 (2), 1-20.

GrYDEHØJ, A. i HAYWARD, P. (2014). "Social and economic effects of spatial distribution in island communities: Comparing the Isles of Scilly and Isle of Wight, UK». Journal of Marine and Island Cultures, 3, 9-19. <https://doi.org/10.1016/j.imic.2014.03.002>

HAY, P. (2006). "A phenomenology of islands». Island Studies Journal, 1 (1), 19-42.

IndovinA, F. (1998). "Algunas consideraciones sobre la ciudad difusa». Documents d'Anàlisi Geogràfica, 33, 21-32.

IOANNIDES, D. i DEBBAGE, K. (1998). The economic geography of the tourist industry: A supply side analysis. Londres: Routledge.

JACKSON, R. E. (2008). Islands on the Edge: Exploring Islandness and Development in Four Australian Case Studies. Universitat de Tasmània. Tesi doctoral.

JudD, D. (2003). The infrastructure of play: Building the tourist city. Nova York: ME Sharpe.

Judd, D. i FAnstein, S. (1999). The tourist city. New Haven CT: Yale University Press.

LEONTIDOU, L. i TOURKOMENIS, K. (2009). «El turismo residencial y la litoralización del Mediterráneo: La migración del norte a las costas meridionales de Europa». A: Mazon, T.; Huete, R. i MANTECón, A. (eds.). Turismo, urbanización y estilos de vida: Las nuevas formas de movilidad residencial. Barcelona: Icaria, 37-54.

LÓPEZ, J. i López, L. (2006). «La concentración estacional en las regiones españolas desde una perspectiva de la oferta turística». Revista de Estudios Regionales, 77, 77-104.

Maccachren, A. M. (1985). "Compactness of Geographic Shape: Comparison and Evaluation of Measures». Geografiska Annaler. Series B. Human Geography, 67 (1), 53-67.

MareZ, I. E. (2012). Movimiento moderno y los proyectos de las estaciones turísticas de Languedoc-Roussillon: La grande-Motte y Port Leucate. Baracrès. Barcelona: UPC.

Martí, P. i Nolasco, A. (2011). "La expansión urbanística reciente de la costa alicantina, una realidad constatable». A: AGE. Urbanismo expansivo de la utopía a la realidad. Universitat d'Alacant: Vicente Gonzálvez Pérez, Juan Antonio Marco Molina. XXII Congreso de Geógrafos Españoles, 367-378.

McElroy, J. (2006). «Small island tourist economies across the lifecycle». Asia Pacific Viewpoint, 47 (1), 61-77. <https://doi.org/10.1111/j.1467-8373.2006.00303.x>

McElroy, J. i Hamma, P. (2010). «SITEs revisited: Socioeconomic and demographic contours of small island tourist economies». Asia Pacific Viewpoint, 51 (1), 36-46. <https://doi.org/10.1111/j.1467-8373.2010.01412.x>

Mestre, M. (2015). "Ciutat i territori a Mallorca: Una revisió de la "macrocefalia" mallorquina». Documents d'Anàlisi Geogràfica, 61 (2), 351-368. <http://dx.doi.org/10.5565/rev/dag.188> 
Moles, A. A. (1982). "Nissonologie ou science des îles». L'Espace Géographique, 4, 281-289. <https://doi.org/10.3406/spgeo.1982.3782>

Monclús, J. (1998). La ciudad dispersa: Urbanismo, Ciudad, Historia (I). Barcelona: Centre de Cultura Contemporània de Barcelona.

Murray, I. (2012). Geografies del capitalisme balear: Poder, metabolisme socioeconòmic i petjada ecològica d'una superpotència turística. Palma: Universitat de les Illes Balears.

Nello, O. (1998). «Los confines de la ciudad sin confines: Estructura urbana y límites administrativos en la ciudad difusa». A: Monclús, F. J. La ciudad dispersa. Barcelona: Centre de Cultura Contemporània de Barcelona.

Norberg-Schulz, C. (1980). Genuis loci: Towards a phenomenology of architecture. Nova York: Rizzoli International Publications, Inc.

Observatorio de la Sostenibilidad en España (OSE) (2006). Cambios de ocupación del suelo en España: Implicaciones para la sostenibilidad. Madrid: Mundi Prensa.

- (2007). Cambios de ocupación del suelo en España: Implicaciones para la sostenibilidad. Alcalá de Henares: Universitat d'Alcalá.

Osserman, R. (1978). "Isopermetric inequality». Bulletin of the American Matematical Society, 84 (6), 1182-1238.

PÉROn, F. (2004). "The Contemporary Lure of the Island». Tijdschrift voor Economische en Sociale Geografie, 95 (3), 326-339. <https://doi.org/10.1111/j.1467-9663.2004.00311.x>

Pintado, F. i Fernández, N. (2010). «Insularity in a Community Framework: The status of the Balearic Islands». A: MANERA, C. i GARAU, J. Insularity in the Mediterranean: Economic and environmental challenges. Madrid: Pirámide.

POns, A. (2003). «Evolució dels usos del sòl a les Illes Balears. 1956-2000». Territoris, 4, 129-145.

- (2016). Turisme, illeïtat $i$ urbanització a les Illes Balears (1956-2006). Palma: Universitat de les Illes Balears. Tesi doctoral dirigida per Onofre Rullan.

POnS, A. i Rullan, O. (2014). «Artificialization and Islandness on the Spanish Tourist Coast». Miscellanea Geographica - Regional Studies on Development, 18 (1), 5-16. <https://doi.org/10.2478/mgrsd-2014-0010>

Pons, A.; Rullan, O. i Murray, I. (2014). "Tourism capitalism and the urbanization of the Balearic Islands: Tourist accomodation difussion in the Balearics (19362010)». Island Studies Journal, 9 (2), 239-258.

Quammen, D. (1996). The song of the Dodo: Island Biogeography in a Age of Extinctions. Londres: Pimlico.

QuintanA, A. (1972). "Las islas Adyacentes de Mallorca». Economia Balear, 46, 15-17.

QUintana Peñuela, A. (1978). «Actividades económicas y urbanización en Mallorca». Trabajos de Geografía, 34, 93-128.

RiCHARDSON, L. (1961). «A note: Measuring compactness as a requirement of legislative apporttionment». Mid-west Journal of Political Science, 5, 70-74.

Rico, A. M.; Olcina, J. i Baños, C. J. (2014). "Competencias por el uso del agua en la provincia de Alicante: Experiencias de gestión en la armonización de usos urbano-turísticos y agrícolas». Documents d'Anàlisi Geogràfica, 60 (3), 523-548. <https://doi.org/10.5565/rev/dag.136>

RoYle, S. A. (1989). «A human geography of islands». Geography, 74 (1), 106-116. 
RugGieri, G. (2011). «Tourism in mediterranean islands: A comparative analysis». A: CARlsen, J. i Butler, R. Island tourism: Sustainable perspectives. CAB International, 186-196. <https://doi.org/10.1079/9781845936792.0186>

Rullan, O. (2002). La construcció territorial de Mallorca. Palma: Moll.

- (2010). «Los efectos territoriales de las dinámicas globales en unas islas turísticas mediterráneas: Las Baleares». El Periplo Sustentable: Turismo y Desarrollo, 18, 119160.

- (2011). "La regulación del crecimiento urbanístico en el litoral mediterráneo español». Ciudad y Territorio: Estudios Territoriales, 168, 279-297.

Sabaté, J. (2015). "Turismo, paisaje i terrazas de cultivo». A: Font, A.; Horrach, B. i Sabaté, J. Paisatges del turisme. Barcelona: UPC, 45-61.

Seguí, J. M. i Martínez, M. R. (1994). «El aeropuerto de Palma en la red del tráfico aéreo de pasajeros: Un anàlisis de relaciones». Boletín de la AGE, 19, 67-88.

Serneels, S. i LAmbin, E. (2001). "Proximate causes of land-use change in Narok District, Kenya: A spatial statistical model». Agriculture, Ecosystems and Environment, 85, 65-81. <https://doi.org/10.1016/s0167-8809(01)00188-8>

Serra, P.; Pons, X. i Saurí, D. (2008). «Land-cover and land-use change in a Mediterranean landscape: A spatial analysis of driving forces integrating biophysicaland human factors». Applied Geography, 28, 189-209. <http://dx.doi.org/10.1016/j.apgeog.2008.02.001>

Simancas, M.; García, J.; DORTA, A. i FAlero, R. (2011). «El impacto territorial de la moratoria turística de Canarias». A: AGE. Urbanismo expansivo de la utopia a la realidad. Universidad de Alicante: Vicente Gonzálvez Pérez, Juan Antonio Marco Molina. XXII Congreso de Geógrafos Españoles, 715-726.

SojA, E. W. (2008). Postmetrópolis. Traducció de V. H. Cifuentes. Madrid: Traficantes de Sueños.

SufRAUJ, S. (2011). «Islandness and remoteness as resources: Evidence from the tourism performance of Small Remote Island Economies (SRIES)». European Journal of Tourism, Hospitality and Recreation, 2 (1), 19-41.

VILlar, A. (2011). Territorio, turismo y paisaje: El proceso de urbanización en el litoral de Andalucía. El papel de los campos de golf. Sevilla: Universitat de Sevilla. Tesi doctoral.

ZORNOZA, C. (2013). Crecimiento urbanístico en la zona costera de la comunidad valenciana, 1987-2009. València: Publicacions de la Universitat de València. 